\title{
The changing trends and tendencies in maternal mortality: a compare and contrast spanning two decades
}

\author{
Arunadevi Govindarajan, Vijayalakshmi Natarajan, Sangeetha Ramesh*
}

Institute of Obstetrics and Gynaecology, Hospital for Women and Child Health, Egmore, Chennai, Tamil Nadu, India

Received: 25 May 2021

Revised: 21 June 2021

Accepted: 22 June 2021

\section{*Correspondence:}

Dr. Sangeetha Ramesh,

E-mail: sangeetha.ramesh4@gmail.com

Copyright: ( ) the author(s), publisher and licensee Medip Academy. This is an open-access article distributed under the terms of the Creative Commons Attribution Non-Commercial License, which permits unrestricted non-commercial use, distribution, and reproduction in any medium, provided the original work is properly cited.

\section{ABSTRACT}

Background: Though the maternal mortality ratio has been on the constant decline over two decades we shall strive forward to prevent all preventable maternal deaths and we have a long way to reach the SDG 3.1 goal. So, it becomes imperative to further reduce the mortality rates by continuously reviewing and upgrading our health policies. The aim of the study was to compare the trends in maternal mortality in 2002-2011 to the current predicament in 2017- 2019 in our hospital.

Methods: Data was collected for all maternal deaths in the Institute of obstetrics and gynaecology, Egmore, Chennaia centre of excellence for maternal care in South India, in terms of age at time of death, parity, period of death, mode of delivery, the cause of death and the admission to delivery interval and compared between the time periods of 2002-2011 and 2017-2019 to identify the changing patterns.

Results: The maternal mortality ratio has consistently declined over the years from 220 in 2002 to 110 in 2019 . The age group of 20-29 years and primigravidae continue to amount for most mortality. The postpartum period remains the most susceptible period. There is a significant increase in the number of caesarean deaths (64\% from 46\%). Significant transition in the cause of death from haemorrhage (20\% to $7 \%$ ) to hypertensive disease of pregnancy (23\% to $35 \%)$ as leading cause of maternal mortality has been witnessed.

Conclusions: Significant difference in the trends over two decades in maternal mortality lies in the fact that the leading cause of maternal mortality has changed from haemorrhage to hypertensive diseases and sepsis and they have continued to occupy the top spots for the past decade. Preventive measures are the solution to reduce maternal mortality due to either of the causes.

Keywords: Maternal mortality ratio, Changing trends, Maternal health policies, Hypertensive diseases of pregnancy spectrum, Haemorrhage

\section{INTRODUCTION}

Maternal mortality has not only been a direct indicator of the efficacy of the health system of the country but also an indirect impactor on the well-being of the society. Reducing maternal mortality has been an inescapable component in all national and global developmental programs. Millennium development goals (MDG) set a target to reduce the maternal mortality ratio (MMR) by three quarters from 1990 to 2015, which loosely translates to a MMR target of 139 in India. ${ }^{1}$ India successfully achieved a MMR of 113 by 2016-2018. ${ }^{2}$ With boosted hope, Indian government strives forward with greater intensity to achieve the sustainable development goal (SDG 3.1) of an MMR of 70 by $2030 .{ }^{3}$ The contribution to MMR throughout the country is not the same where states like Tamil Nadu has already achieved the MMR of 60 according to the SRS bulletin. ${ }^{2}$ But pregnancy and childbirth being a natural process, it becomes our utmost responsibility to ensure it is a safe experience for both the mother and the child. And for every death, there are many more women who suffer varying degrees of morbid 
conditions. So, it becomes imperative to relentlessly work to further reduce the mortality and morbidity rates by continuously reviewing and upgrading our health policies. The aim of the study was to compare the trends in maternal mortality in 2002-2011 to the current predicament in 20172019 in our hospital- centre of excellence in providing maternity care in South India.

\section{Objectives}

The objective of this study were- (a) to compare the various factors attributable to maternal mortality in the years 2002 -2011 with the variables in 2017-2019 and provide insight on the changing patterns in our hospital. The variables under this study included age, parity, period of death, mode of delivery, cause of death, and admission to death interval; (b) to analyse the new pattern in maternal mortality in terms of its cause and provide intel to prevent further maternal mortality due to the same.

\section{METHODS}

It was an observational study comparing the trends of maternal mortality in the Institute of obstetrics and gynaecology, Egmore, Chennai- a centre of excellence for maternal care in South India during the periods of 20022011 and 2017-2019. All maternal deaths that occurred during the study period in the Institute of obstetrics and gynaecology, Egmore during the study periods were included, including cases transferred out for multidisciplinary care to our allied institutes. Only one case, brought dead to the casualty was excluded.

Data regarding the maternal mortality from the years of 2002-2011 was gathered from the institutional maternal mortality audit registry. And data of the maternal deaths from the years 2017-2019 were collected from the case records from the medical records department. Data in terms of age at time of death, parity, period of death (antepartum or postpartum), mode of delivery if postpartum including curettage or evacuation procedures for cases of abortion, the cause of death and the admission to delivery interval was diligently tabulated.

In the dilemma of assigning the cause of death where multiple causes contributed to the death of the mother, the major contributing factor was taken to be the cause.

The variables amounting to maternal mortality were compared and statistical significance ascertained using SPSS version 26 between the two time periods of study.

\section{RESULTS}

Maternal mortality ratio was calculated using the standard formula of number of maternal deaths irrespective of gestational age up to 42 days postpartum per 1,00,000 live births during the same time period not including accidental causes of maternal death. The maternal mortality has evidently shown a decreasing trend in our institute more so in the years of 2017-2019 in congruence with the maternal mortality ratios of the state Tamil Nadu and country India.

The women of 20-29 years continue to be the maximum affected age group amounting to $66.8 \%$ in the previous decade and $70.2 \%$ of the affected population in the years 2017-2019. The teenage pregnancies leading to maternal mortality have shown a sharp decline from $8 \%$ to $1 \%$ $(\mathrm{p}=0.01)$. The number of women of age more than 40 years have shown a 10 -fold increase in death rate from $0.2 \%$ to $2 \%$. The trends of parity have not showed much difference over the time periods with maximum deaths occurring in the primigravida ( $47 \%$ to $53 \%$ ) when compared to higher order births.

Postpartum period appears to be the period of high risk for maternal mortality claiming $82 \%$ of the maternal deaths in the recent years similar to the rate of $87 \%$ of postpartum maternal deaths in 2002-2011. However, there was a tilt in the trends towards increased caesarean section mortality $(64 \%)$ when compared with that following labour natural $(24 \%) \quad(\mathrm{p}=0.007)$. The percentage of deaths in the immediate 24 hours of admission have seen a very significant decline from $57 \%$ to $26 \%$ in the compared time groups. And the deaths occurring more than 1 week since admission have significantly increased to $33 \%$ from a mere $9 \%$ in the yesteryears.

The longest admission to delivery interval was 31 days 21 hours in a case of disseminated tuberculosis (TB)/recurrent pericardial effusion/left pleural effusion/TB spondylodiscitis with arachnoiditis/disseminated intra vascular coagulation (DIC)/hypoxic ischemic encephalopathy (HIE) and the shortest admission to death interval was 30 mins in a case of traumatic PPH leading to hypovolumic shock.

Hypertensive diseases in pregnancy persist to dominate the maternal mortality scene occupying $23 \%$ of the cause for death in 2002-2011 only to increase to $35 \%$ in 2017-2019. Postpartum haemorrhage has however been dethroned now amounting only to $7 \%$ of the maternal mortality $(p=0.003)$. Sepsis $(20 \%)$ and heart diseases $(15 \%)$ have raced to claim the second and third most important causes of maternal mortality in the recent years when compared to their contribution of $15 \%$ and $13 \%$ respectively previously.

The other medical conditions, most importantly anaemia and it's complications $(\mathrm{N}=2)$, followed by pre-existing neurological conditions $(\mathrm{N}=3)$, catastrophic anti phospholipid antibody syndrome (APLA) or systemic lupus erythematosis (SLE) flare $(\mathrm{N}=2)$, decompensated chronic liver disease (DCLD) $(\mathrm{N}=1)$, acute leukaemia $(\mathrm{N}=1)$, viral pneumonia $(\mathrm{N}=3)$, diabetic ketoacidosis (DKA) $(\mathrm{N}=1)$, gastro intestinal lymphoma $(\mathrm{N}=1)$ and disseminated TB $(\mathrm{N}=1)$ contribute to $15 \%$ of the maternal deaths. Figure 1 gives the pareto analysis of causes of maternal mortality over the years. In the in depth analysis of the maternal deaths in recent years of 2017-2019 it was 
elucidated that the most important cause of death in the immediate 24 hours of admission was hypertensive disease of pregnancy spectrum $(\mathrm{N}=11)$ with deaths being either direct cause of intrapartum eclampsia $(\mathrm{N}=4)$, refractory pulmonary edema $(\mathrm{N}=2)$, intractable hemolysis, elevated liver enzymes and low platelets (HELLP) with Multi organ dysfunction syndrome (MODS) $(\mathrm{N}=5)$. Disseminated intra vascular coagulation (DIC) was found to be the inevitable accompaniment of most cases of severe preeclampsia spectrum and sepsis culminating in deaths $(\mathrm{N}=10)$. Figure 3 gives the immediate causes of maternal mortality within 24 hours of admission.

Table 1: Compare and contrast of factors causing maternal mortality.

\begin{tabular}{|c|c|c|c|c|c|}
\hline Variables & $2002-2011(\mathrm{~N}=360)$ & $2002-2011(\%)$ & $2017-2019(\mathrm{~N}=99)$ & $2017-2019(\%)$ & P value \\
\hline \multicolumn{6}{|l|}{ Age (years) } \\
\hline$<20$ & 30 & 8 & 1 & 1 & 0.01 \\
\hline $20-29$ & 240 & 66.8 & 70 & 70.2 & 0.447 \\
\hline $30-39$ & 89 & 25 & 26 & 26.8 & 0.754 \\
\hline$>40$ & 1 & 0.2 & 2 & 2 & 0.057 \\
\hline \multicolumn{6}{|l|}{ Parity } \\
\hline 1 & 169 & $47 \%$ & 53 & $53.00 \%$ & $\mathrm{~N} / \mathrm{S}$ \\
\hline 2 & 99 & $27.50 \%$ & 26 & $26 \%$ & $\mathrm{~N} / \mathrm{S}$ \\
\hline 3 & 63 & $17.50 \%$ & 13 & $13 \%$ & $\mathrm{~N} / \mathrm{S}$ \\
\hline$>3$ & 29 & $8 \%$ & 7 & $7 \%$ & $\mathrm{~N} / \mathrm{S}$ \\
\hline \multicolumn{6}{|l|}{ Period of death } \\
\hline Antepartum & 47 & 13 & 18 & 18 & $\mathrm{~N} / \mathrm{S}$ \\
\hline Postpartum & 313 & 87 & 81 & 82 & $\mathrm{~N} / \mathrm{S}$ \\
\hline \multicolumn{6}{|l|}{ Mode of delivery } \\
\hline LSCS & 144 & 46 & 51 & 64 & 0.007 \\
\hline Labour natural & 122 & 39 & 19 & 24 & 0.009 \\
\hline $\begin{array}{l}\text { Abortion/spontane } \\
\text { ous expulsion }\end{array}$ & 33 & 10.5 & 8 & 9 & 0.861 \\
\hline $\begin{array}{l}\text { Instrumental } \\
\text { delivery }\end{array}$ & 14 & 4.5 & 3 & 3 & 0.761 \\
\hline \multicolumn{6}{|c|}{ Admission to death interval } \\
\hline$<24$ hours & 205 & 57 & 26 & 26 & 0.000000064 \\
\hline 24 hours- 72 hours & 82 & 23 & 13 & 13 & 0.035894312 \\
\hline 72 hours-1 weeks & 39 & 11 & 28 & 28 & 0.000013313 \\
\hline$>1$ week & 34 & 9 & 32 & 33 & 0.000000009 \\
\hline \multicolumn{6}{|l|}{ Cause of death } \\
\hline $\begin{array}{l}\text { Antepartum } \\
\text { hemorrhage }\end{array}$ & 24 & 7 & 3 & 3 & 0.1733 \\
\hline $\begin{array}{l}\text { Postpartum } \\
\text { hemorrhage }\end{array}$ & 71 & 20 & 7 & 7 & 0.003 \\
\hline $\begin{array}{l}\text { Hypertensive } \\
\text { disease of } \\
\text { pregnancy }\end{array}$ & 85 & 23 & 35 & 35 & 0.0185 \\
\hline Sepsis & 53 & 15 & 20 & 20 & 0.0185 \\
\hline Heart disease & 46 & 13 & 15 & 15 & 0.1867 \\
\hline $\begin{array}{l}\text { Amniotic fluid } \\
\text { embolism }\end{array}$ & 10 & 3 & 0 & 0 & 0.5378 \\
\hline Septic abortion & 5 & 1 & 3 & 3 & 0.0936 \\
\hline Obstructed labour & 0 & 0 & 0 & 0 & 0.2691 \\
\hline $\begin{array}{l}\text { Other medical } \\
\text { condition }\end{array}$ & 66 & 18 & 14 & 15 & 0.3302 \\
\hline $\begin{array}{l}\text { Trauma/anaesthetic } \\
\text { complication }\end{array}$ & 0 & 0 & 2 & 2 & 0.0069 \\
\hline
\end{tabular}

*N/S- Not significant statistically. 


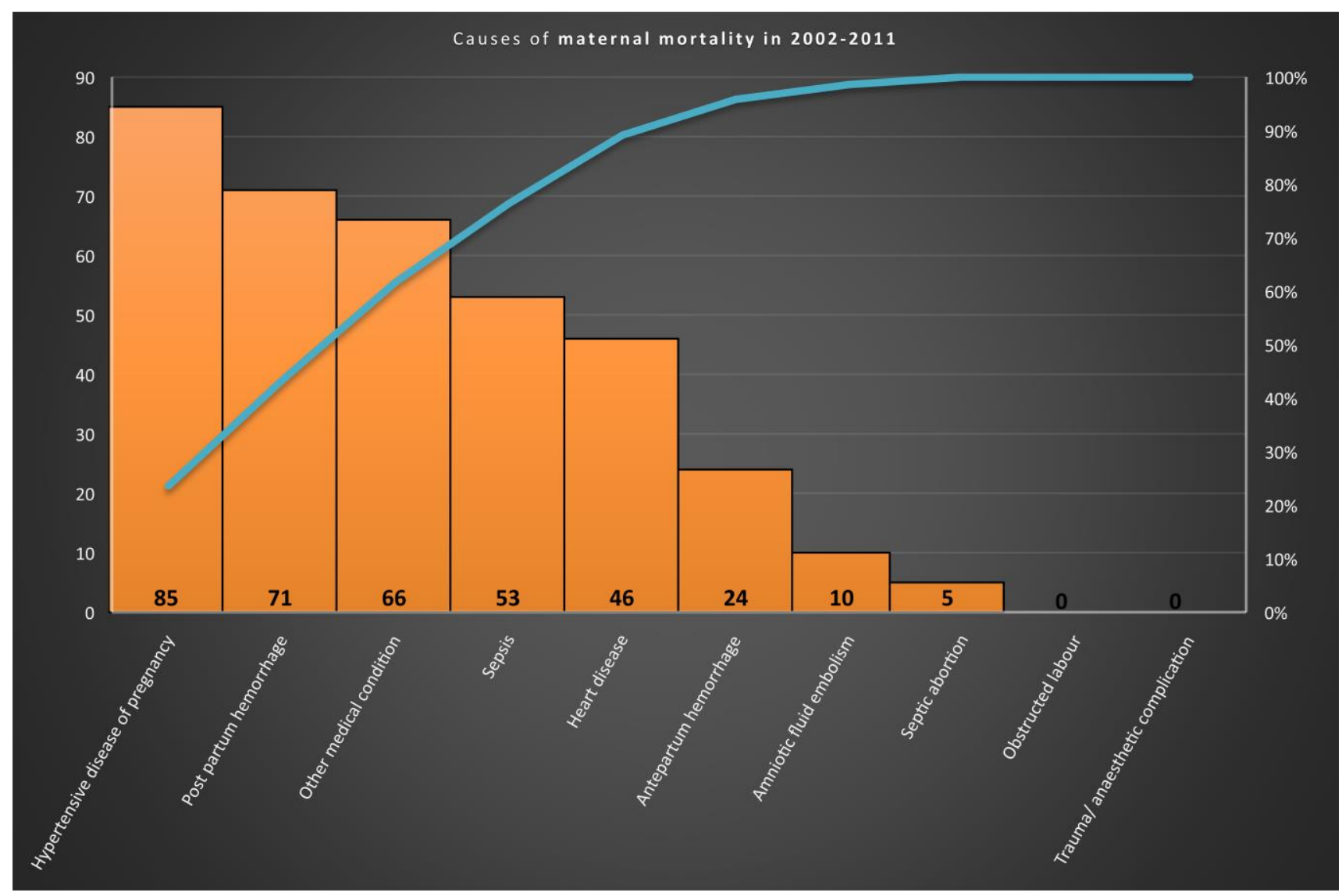

Figure 1: Causes of maternal mortality in 2002-2011.

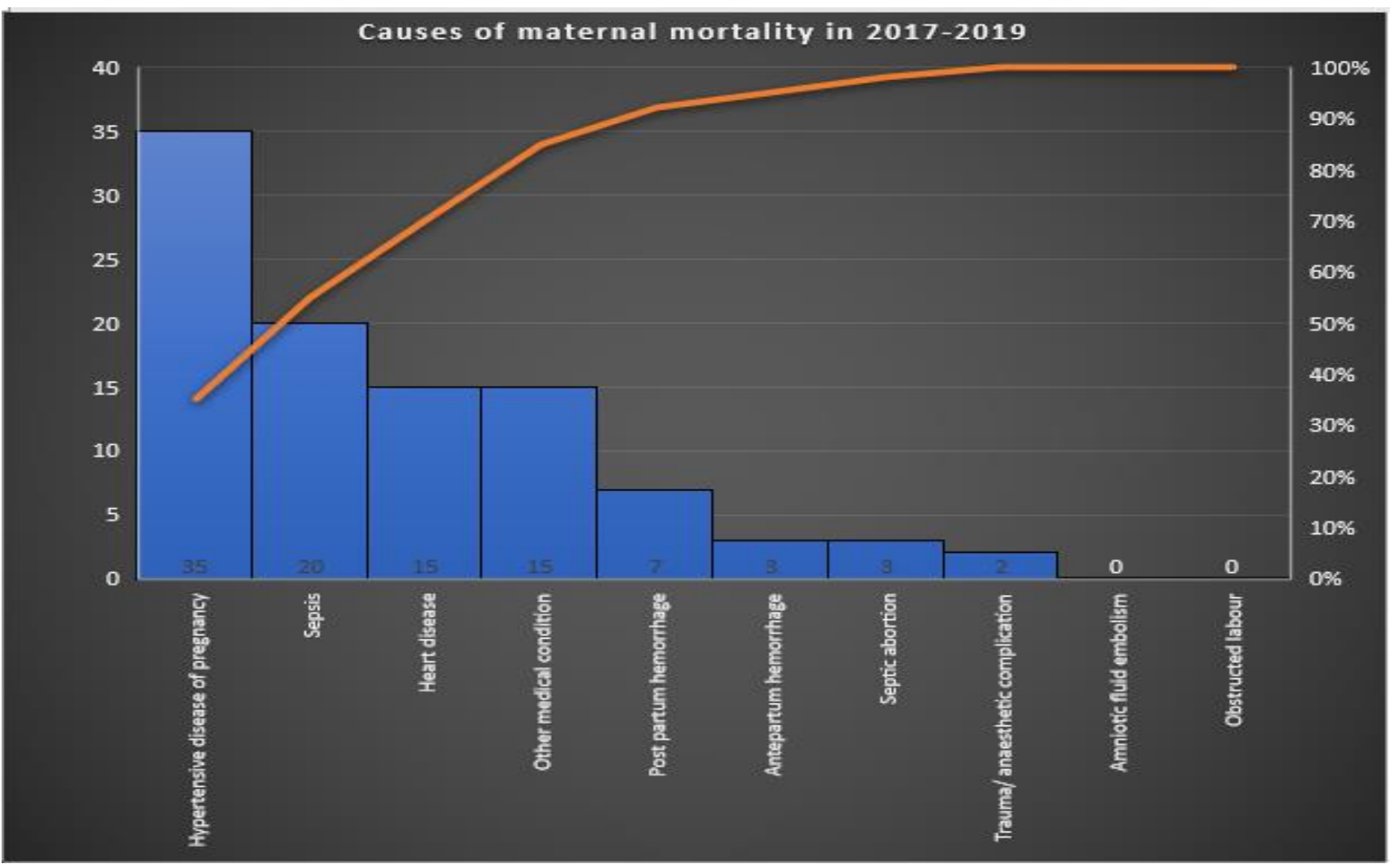

Figure 2: Causes of maternal mortality in 2017-2019. 


\section{Cause of death $<24$ hours of admission}

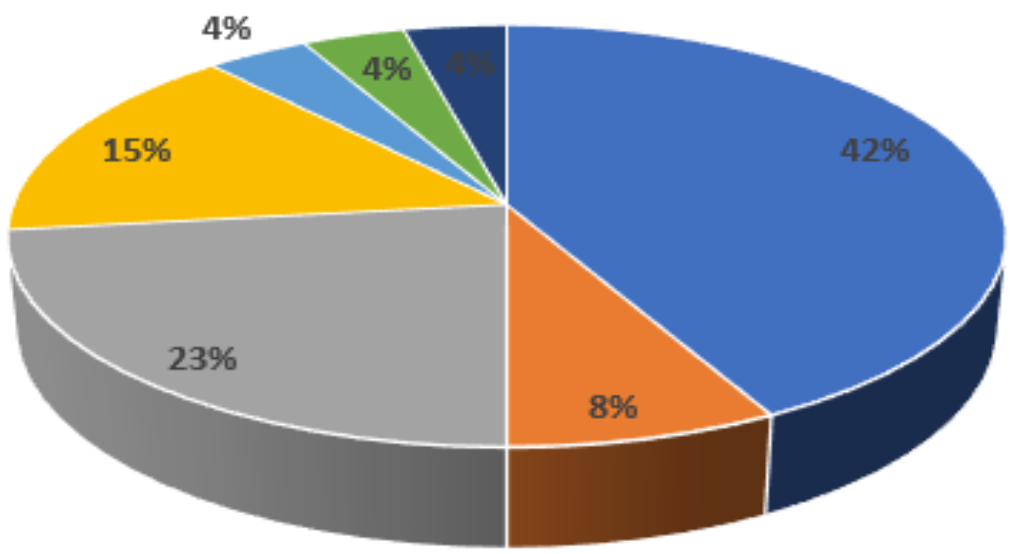

- Preeclampsia/ Eclampsia

- Post partum hemorrhage

- Sepsis

- Heart disease

- Ruptured ectopic

- Septic abortion

- Anemia

Figure 3: Causes of maternal mortality in $<24$ hours of admission.

\section{DISCUSSION}

From 2000 to 2017, the global maternal mortality ratio declined by 38 per cent- from 342 deaths to 211 deaths per 100,000 live births, according to United Nations (UN) inter-agency estimates. ${ }^{4}$ Keeping pace with the global standards, MMR of India declined by $33 \%$, however the MMR of our institute surpasses the standards by having dwindled $50 \%$ - 220 death to 110 deaths per 100,000 live births from 2002 to $2019 .{ }^{4}$

Studies on the changing trends in maternal mortality is not a paucity with every study boasting the decline in the mortality ratio. It is evidence to the successful execution of the multitude of government health programmes aimed at improving maternal health. Since the inception of Reproductive and Child Health(RCH) programme in 1997, Indian government has been striving hard to provide better maternal care evidenced by the implementation of Janani Suraksha Yojana (JSY) in April 2005 with the objective of reducing Maternal and infant mortality - a conditional cash transfer scheme for pregnant women coming into the institutional fold for delivery, followed by the launch of Janani Shishu Suraksha Karyakram (JSSK) in 2011 to eliminate out of pocket expenditure for pregnant women and sick new borns delivering in public health institutions entitling them to no expense delivery including free Caesarean section, free drugs, diet, referral and transport facilities. $^{5}$ Reproductive, Maternal and Child Health+Adolescents ( $\mathrm{RMCH}+\mathrm{A})$ approach launched in 2013 essentially looks to address the major causes of mortality among women and children as well as the delays in accessing and utilising health care and services including provision of Comprehensive Abortion Care and Family Planning services. Maternal Death Review system (MDRS) process initiated by the government in 2010 provides to analyse lacunae in maternal health system in facility, community, district regional and national level to reduce the maternal mortality. ${ }^{1}$ PMSMA (Pradhan Mandhri Surakshit Matritva Abhiyan) has been introduced in 2016 where all pregnant women are provided a minimum package of antenatal care services (including investigations and drugs). LaQshya programme has been launched in 2017 with the aim to improve the quality of care in Labour room and Maternity operation theatres. ${ }^{6}$ Hence its prudent to compare the trends of maternal mortality before the execution of these programs with the period where the results of the national programs are reflected (2017-2019) making this study justifiable and significant.

The number of teenage pregnancies have reduced from $7.7 \%$ in 2005-2006 to 5\% in 2015-2016 accounting for the lesser number of teenage maternal mortality in our study in the recent years of 2017-2019. ${ }^{7}$ However, Ashraf et al in his study in 2008-2013 showed women of age less than 20 contributed to $10.6 \%$ of the MMR in their institute. ${ }^{8}$ The largest number of deaths occur in the age group of 2039 years, largely because those are the ages at which women are most likely to give birth, as mirrored in the present study. Maternal mortality age patterns across world show a $\mathbf{J}$ shaped curve with markedly higher risk after age $30 .{ }^{9,10}$ Though women in age group of more than 40 have increased risk of pregnancy induced morbidity there were no significant differences in pregnancy outcomes or obstetrical outcomes between older and younger mothers, provided that (especially older) mothers were careful to treat their preexisting chronic disease pregnancy-induced morbidity monitored regularly or controlled medically and delivered in a perinatal centre. ${ }^{11}$ But the current study shows a steep significant increase in mortality in the older age group. In a study on maternal mortality during 1985-1994, multigravidae were more susceptible to mortality $(55.78 \%) .{ }^{12}$ The trend continues to 
2008-2011, but the difference in mortality percentage between multigravidae $(51 \%)$ and primigravida $(42 \%)$ lessen. ${ }^{13}$ And then, in the following studies and as in the present study there is a transition to increasing primigravida succumbing. ${ }^{14}$ Higher order births have higher risk of pregnancy induced morbidities and are managed as high risk pregnancies in referral units. Essential obstetric care mandated to all pregnant mothers (low risk primigravidae) enables early identification of risk factors and prevention of maternal mortality.

The detailed analysis of the deaths in the years 2017-2019 imply the preponderance of maternal deaths in the postpartum period may be due to the need for accelerated delivery of the fetus in view of deteriorating maternal health and emergency caesarean section has been sought out to be the preferred mode of delivery. Therefore, the significance of increased predilection of maternal deaths in the postpartum period continues to be a matter of uncertainty. The causes absolutely specific to the postpartum period like postpartum haemorrhage $(7 \%)$ or postpartum complication in cardiovascular diseases (one case of prosthetic valve thrombosis, and one case of congestive cardiac failure in known RHD due to post op fluid overload), intra operative mishaps (one case of colonic perforation leading to perforation peritonitis), anaesthetic complications $(\mathrm{N}=0)$ or postoperative sepsis (onset of symptoms of sepsis more than 72 hours, $\mathrm{N}=6$ ) contribute significantly lesser to maternal mortality. One third of the complications arose in pregnancy prior to onset of labour. Hence care should be taken not to misclassify maternal deaths as intrapartum or postpartum, as delivery is the preferred management in most conditions. ${ }^{15}$

Regional and global estimates of distribution of causes of maternal death by WHO systematic analysis between 2003-2009 showed that nearly $73 \%$ of all maternal deaths were due to direct obstetric causes whereas deaths due to indirect causes accounted for 27.5\% (95\% UI 19.7-37.5). Haemorrhage was the leading direct cause of maternal death worldwide, representing $27.1 \%$ (19.9-36.2) of maternal deaths, followed by hypertension spectrum (14.0\%, 11.1-17.4). Maternal mortality due to sepsis was $10.7 \%$ (5.9-18.6), abortion accounted for $7.9 \%$ (4.7-13.2), and embolism and other direct causes accounted for the remaining $12.8 \%$ of global deaths. ${ }^{16}$ As per the RGI-SRS (Registrar General of India- Sample Registration System) report titled 'Maternal mortality in India: 2001-2003 trends, causes and risk factors', major causes of maternal deaths in the country were haemorrhage (38\%), sepsis $(11 \%)$, hypertensive disorders $(5 \%)$, obstructed labour (5\%), abortion (8\%) and other Conditions (34\%), which includes anaemia. Though the exact point of transition could not be pinpointed, Verma et al in 1995-2005 highlighted how toxaemia of pregnancy $(20 \%)$ and sepsis $(21.6 \%)$ were catching up to haemorrhage $(21.8 \%)$ as the leading cause of maternal mortality. ${ }^{17}$ In the study by Mukherjee et al in 1996-2006 toxaemia shows a clear dominance with $22.97 \%$ over haemorrhage contributing $12.7 \%$ to the cause of deaths. ${ }^{18}$ The pattern of hypertensive disease spectrum dominating as the cause of maternal mortality is established in 2008-2013 where Ashraf Ali et al confirms toxaemia attributes $30.4 \%$ and haemorrhage $24.8 \%$. The pattern has persisted till date as evident in the present study with hypertensive diseases and sepsis being the clear killers.

The transition to newer causes of maternal mortality can be explained by the rapid reduction in the rates of postpartum haemorrhage by improving increased institutional delivery (98.9\% according to NFHS4 Tamil Nadu fact sheet 2015-2016), active management of Third stage of labour, prompt referral services, improved availability of blood and blood products and improved antenatal correction of anaemia. All these interventions have been components of the multiple national programs and evident reduction of postpartum haemorrhage is the proud reflection of their successful implementation. Despite the increasing use of antibiotics the rising rates of sepsis remains an enigma. LaQshya program implemented in 2017 aims to provide better labour room qualities hoping to mitigate this risk of sepsis.

Hypertensive diseases of pregnancy have now remained an unresolved problem for over a decade. In a sub-Saharan African study, Goldenberg et al suggests that early identification of hypertensive disease of pregnancy, transfer to higher levels of care and increased hospitalisation with cesarean section/induction of labor would substantially reduce maternal mortality from hypertensive diseases. Increasing use of $\mathrm{MgSO}_{4}$ would have a smaller impact on maternal mortality. ${ }^{19}$ Clark et al reported a dramatically reduced number of deaths due to preeclampsia after implementing disease-specific protocols with clear blood pressure thresholds and an emphasis on prompt recognition and management of preeclampsia. ${ }^{20}$ Similarly, Herrera et al were able to decrease the number of maternal deaths from preeclampsia by one-fifth by implementing guidelines for preventive care in high-risk preeclampsia patients. ${ }^{21}$

Preventive care like monitoring BP, proteinuria, routine antenatal care for early identification of hypertensive diseases, extra vigilance if previous history of severe preeclampsia, regular $\mathrm{BP}$ monitoring and aggressive antihypertensive treatment to maintain BP under target threshold in known cases, induction at 37 completed weeks, magnesium sulphate for the prevention of eclampsia fits, ICU care, post-operative judicious fluid management, prompt recognition of complications like HELLP, DIC and emergent management of the same serve as the corner stone to prevent preeclampsia/eclampsia related deaths. ${ }^{22}$

There is always an inverse and significant correlation of the maternal mortality ratio with Antenatal care coverage, skilled birth attendance, early referral services and standardised disease and patient specific care and a positive correlation with disease incidence and unmet needs. 
The study was limited by the fact that it is done in a tertiary care centre which caters to only high-risk maternal population and so the data cannot be generalised on a national level. This study highlights only the differences in the trends and the possible niches for intervention between the two time periods studied but a causal relationship between any of the interventions and the reduction of the mortality rate requires further detailed study.

\section{CONCLUSION}

Significant difference in the trends over two decades in maternal mortality lies in the fact that the leading cause of maternal mortality has changed from haemorrhage to hypertensive diseases and sepsis and they have continued to occupy the top spots for the past decade. Preventive measures are the solution to reduce maternal mortality due to either of the causes. Effective utilisation of the government programmes can prove to further reduce the maternal mortality.

\section{ACKNOWLEDGMENTS}

Our sincere thanks and gratitude to Dr. S. Vijaya, MD, DGO, Director of Institute of Obstetrics and Gynaecology, for granting us permission to use the facilities of the Institute for our study.

Funding: No funding sources Conflict of interest: None declared

Ethical approval: Not required

\section{REFERENCES}

1. National Health Mission. Guidelines for maternal death surveillance and response- National Health Mission, 2017. Available at: https://nhm.gov.in/imageprogrammesmaternalhealth guidelines. Accessed on 13 May 2021.

2. GOI. Special bulletin on maternal mortality in India 2016-2018, 2020. Available at: https://censusindia.gov.in/vital_statistics/SRS_Bullet ins/MMR\%20Bulletin\%202016-18.pdf. Accessed on 13 May 2021.

3. United Nations. Sustainable Development Goals, Goal 3 targets, 2021. Available at: https://www.un.org/sustainabledevelopment/health/. Accessed on 13 May 2021.

4. UNICEF. Trends in estimates of maternal mortality ratio (MMR), maternal deaths and lifetime risk of maternal death, 2000-2017, 2017. Available at: https://data.unicef.org/wpcontent/uploads/2015/11/M MR-maternal-deaths-andLTR_MMEIGtrends_20002017-revised.xlsx. Accessed on 13 May 2021.

5. NHS. Maternal Health Program Annual Report 20132014- National Health Mission, 2014. Available at https://main.mohfw.gov.in/sites/default/files/Chapter 415.pdf. Accessed on 13 May 2021.

6. Surakshit Matritva Ashwasan (SUMAN). Standard Operational Guidelines- National Health Mission,
2021. Available at: http://www.nhm.gov.in/index1.php?lang=1\&level=3 $\&$ sublinkid $=839 \&$ lid $=377$. Accessed on 13 May 2021.

7. Ministry of Health and Family Welfare, GOI. State fact sheet- Tamil Nadu- National Family Health Survey 4. 2015-2016, 2016. Available at: r chiips.org/nfhs/pdf/NFHS4/TN_FactSheet.pdf. Accessed on 13 May 2021.

8. Ashraf AM, Babitha MC, Lokeshchandra HC, Sharma KD, Zehra M, Reddy MS. A study of changing trends of maternal mortality at the tertiary care centre, MMC \& RI Mysore, India. Int J Reprod Contracept Obstet Gynecol 2015;4:239-42.

9. Nove A, Matthews Z, Neal S, Camacho AV. Maternal mortality in adolescents compared with women of other ages: evidence from 144 countries. Lancet Glob Health. 2014;2(3):155-64.

10. Blanc AK, Winfrey W, Ross J. New findings for maternal mortality age patterns: aggregated results for 38 countries. PLoS One. 2013;8(4):59864.

11. Dietl A, Cupisti S, Beckmann MW, Schwab M, Zollner U. Pregnancy and Obstetrical Outcomes in Women Over 40 Years of Age. Geburtshilfe Frauenheilkd. 2015;75(8):827-32.

12. Arup KM, Sanyal P, Chakraborty B. Changing trends in maternal mortality at a teaching cum referral hospital. J Obstet Gynecol India. 1996;345-51.

13. Soni M, Agrawal S, Soni P, Mehra H. Causes of Maternal Mortality: Our Scenario. J South Asian Feder Obst Gynaecol. 2013;5(3):96-8.

14. Onakewhor JU, Gharoro EP. Changing trends in maternal mortality in a developing country. Niger $\mathbf{J}$ Clin Pract. 2008;11(2):111-20.

15. Montgomery AL, Ram U, Kumar R, Jha P, Million Death Study Collaborators. Maternal mortality in India: causes and healthcare service use based on a nationally representative survey. PLoS One. 2014;9(1):83331.

16. Say L, Chou D, Gemmill A, Tunçalp O, Moller AB, Daniels J, Temmerman M, et al. Global causes of maternal death: a WHO systematic analysis. Lancet Glob Health. 2014;2(6):323-33.

17. Verma A, Minhas S, Sood A. A study on maternal mortality in Dr. Rajendra Prasad Govt. M.C. Tanda Dist. Kangra, H.P. (Jan. 1999-Dec. 2005). Indian J Obstet Gynaecol. 2008;58(3):226-9.

18. Mukherjee S, Theengh C, Bhattacharya S, Maru L. Maternal mortality at a tertiary care institute of central India. Asian J Obstet Gynaecol Pract. 2010;4:23-7.

19. Goldenberg RL, Jones B, Griffin JB, Rouse DJ, Kamath BD, Trivedi N, et al. Reducing maternal mortality from preeclampsia and eclampsia in lowresource countries--what should work? Acta Obstet Gynecol Scand. 2015;94(2):148-55.

20. Clark SL, Christmas JT, Frye DR, Meyers JA, Perlin JB. Maternal mortality in the United States: predictability and the impact of protocols on fatal postcesarean pulmonary embolism and hypertension- 
related intracranial hemorrhage. Am J Obstet Gynecol. 2014;211(1):32.

21. Herrera JA, Herrera MR, Herrera JP, Nieto A. Reduction of maternal mortality due to preeclampsia in Colombia--an interrupted time-series analysis. Colomb Med. 2014;45(1):25-31.

22. Nyflot LT, Ellingsen L, Yli BM, Oian P, Vangen S. Maternal deaths from hypertensive disorders: lessons learnt. Acta Obstet Gynecol Scand. 2018;97(8):97687.

Cite this article as: Govindarajan A, Natarajan V, Ramesh S. The changing trends and tendencies in maternal mortality: a compare and contrast spanning two decades. Int J Reprod Contracept Obstet Gynecol 2021;10:2704-11. 